\title{
Non-Mental Health Workers' Attitudes and Perceptions Towards People with Mental IIIness in a Tertiary Health Facility in Damaturu, North East Nigeria
}

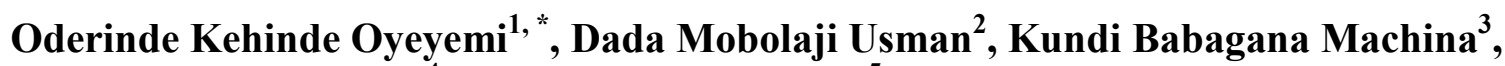 \\ Tsuung Ason Benjamin ${ }^{4}$, Ahmed Hauwa Kudale ${ }^{5}$, Dahiru Asmau Mohammed Chubado ${ }^{5}$, \\ Tanko Salihu Tanimu ${ }^{6}$, Yusuff Alhaji Abdulkareem ${ }^{6}$, Ezra-Oderinde Wonderful Efosa ${ }^{7}$, \\ Awunor Nyemike Simeon ${ }^{8}$, Umar Mohammed Abubakar? \\ ${ }^{1}$ Department of Mental Health and Substance Addiction Treatment, Yobe State University Teaching Hospital, Damaturu, Nigeria \\ ${ }^{2}$ Department of Psychiatry, Ekiti State University Teaching Hospital, Ado Ekiti, Nigeria \\ ${ }^{3}$ Department of Psychiatry, Yobe State Specialist Hospital, Damaturu, Nigeria \\ ${ }^{4}$ Department of Family Medicine, Yobe State University Teaching Hospital, Damaturu, Nigeria \\ ${ }^{5}$ Department of Mental Health, Federal Neuro-Psychiatric Hospital, Maiduguri, Nigeria \\ ${ }^{6}$ Department of Family Medicine, Aminu Kano Teaching Hospital, Kano, Nigeria \\ ${ }^{7}$ Clinical Psychology Unit, Federal Neuro-Psychiatric Hospital, Uselu, Benin City, Nigeria \\ ${ }^{8}$ Department of Community Medicine, College of Health Sciences, Delta State University, Abraka, Nigeria \\ ${ }^{9}$ Department of Medical Laboratory Science, University of Maiduguri, Maiduguri, Nigeria
}

Email address:

psymedrecoverycentre@gmail.com (O. K. Oyeyemi)

${ }^{*}$ Corresponding author

\section{To cite this article:}

Oderinde Kehinde Oyeyemi, Dada Mobolaji Usman, Kundi Babagana Machina, Tsuung Ason Benjamin, Ahmed Hauwa Kudale, Dahiru Asmau Mohammed Chubado, Tanko Salihu Tanimu, Yusuff Alhaji Abdulkareem, Ezra-Oderinde Wonderful Efosa, Awunor Nyemike Simeon, Umar Mohammed Abubakar. Non-Mental Health Workers' Attitudes and Perceptions Towards People with Mental Illness in a Tertiary Health Facility in Damaturu, North East Nigeria. American Journal of Psychiatry and Neuroscience. Vol. 6, No. 2, 2018, pp. 46-50. doi: 10.11648/j.ajpn.20180602.13

Received: May 5, 2018; Accepted: June 5, 2018; Published: July 9, 2018

\begin{abstract}
Health workers are not completely free from the myths, unfavourable beliefs and unpleasant attitudes towards people with mental illness. Most of these perceptions and attitudes towards mental illness are far from the scientific view and these may negatively affect treatment seeking and adherence. However, there is need for mental health education, advocacy and awareness among health workers in order to reduce stigma against mental illness and deepen their supportive roles in the delivery of mental health services.
\end{abstract}

Keywords: Non-Mental Health Workers, Attitudes and Perception, Mental Illness

\section{Introduction}

The myths, beliefs and attitudes about mental illness among health workers can influence clinical outcomes of patients with mental illness [1]. World Health Organization recommends integration of mental health services into general medical services, however, there is growing awareness that mental illness is surrounded by negative attitudes and stigma among health professionals [2]. The misunderstanding of mental illness by the health workers often deprives the psychiatric patients of provision of satisfactory mental and physical healthcare services, thereby endorsing negative attitudes by the society towards them [3]. This has also been shown to inhibit help seeking behavior among people in need of mental health intervention [4].

The stigma, discrimination and negative attitudes 
associated with mental illness has been strongly associated by the World Health Organization with suffering, disability and poverty and a major barrier to treatment [5]. Negative attitude is also a major reason why patients with mental illness fail to acknowledge their illness and it has been described as one of the major factors mitigating their reintegration into the society [6].

Among healthcare workers, studies have documented their negative attitudes towards mental illness [7, 8]. Corrigan further reported that the reason why people often decide not to seek psychiatric services is due to the stigma and negative attitudes associated with seeking these services [9]. Individuals who seek psychiatric services are viewed as less socially acceptable and receive more negative treatment among health workers [10].

The tolerance and positive attitudes of health workers towards people with mental illness is essential for their clinical recovery [11], therefore, the focus on this study is aimed at determining the attitudes and perceptions of non mental health workers towards people with mental illness. Findings from this study may play a significant role in shaping their attitudes in the care of the mentally ill and thereby protecting their rights.

\section{Materials and Methods}

\subsection{Setting of Study}

The study was cross sectional descriptive, conducted in Yobe State Specialist Hospital, Damaturu in the North Eastern geographical zone of Nigeria. The hospital is a tertiary health facility and has a psychiatric department with two full time consultant psychiatrists, two locum consultant psychiatrists and three psychiatric nurses providing mental health services to the people of Yobe State, neigh bouring states in the north eastern region of Nigeria and the West
African sub region as well. It has a staff strength of 243 non mental health workers comprising of 41 doctors, 162 nurses, 2 pharmacists, 2 physiotherapists, 11 laboratory scientists, 13 community health extension workers and 12 medical records keepers.

\subsection{Study Design}

The study protocol was submitted to the Research and Ethical Committee of Yobe State Specialist Hospital, Damaturu and ethical approval obtained. Participation was made voluntary and informed consent was freely obtained from the respondents. Confidentiality was ensured by not indicating the names of the respondents on the questionnaires. Only participants who were non mental health workersin the hospital and who gave their consent were included in the study. Data was collected using a socio demographic questionnaire and attitudes to mental illness was evaluated using the Attitudes to Mental Illness Questionnaire (AMIQ). The AMIQ constructed for this study was designed to explore respondent's knowledge, identified areas of beliefs, perceptions, attitudes to mental illness and treatment modalities. The questionnaires were pre-tested on health workers of different cadres in Yobe State University Teaching Hospital who would not participate in the main study. The aim of this pilot study was to ensure that these questionnaires could reliably be used among the target sample to be recruited for the study.

\subsection{Data Analysis}

Data analysis was carried out using the Statistical Package for Social Sciences version 21 software. To achieve the objectives of the study, appropriate descriptive statistics using means, standard deviation, frequencies and percentage were used for the data collected. Data was presentedin prose, tables and figures.

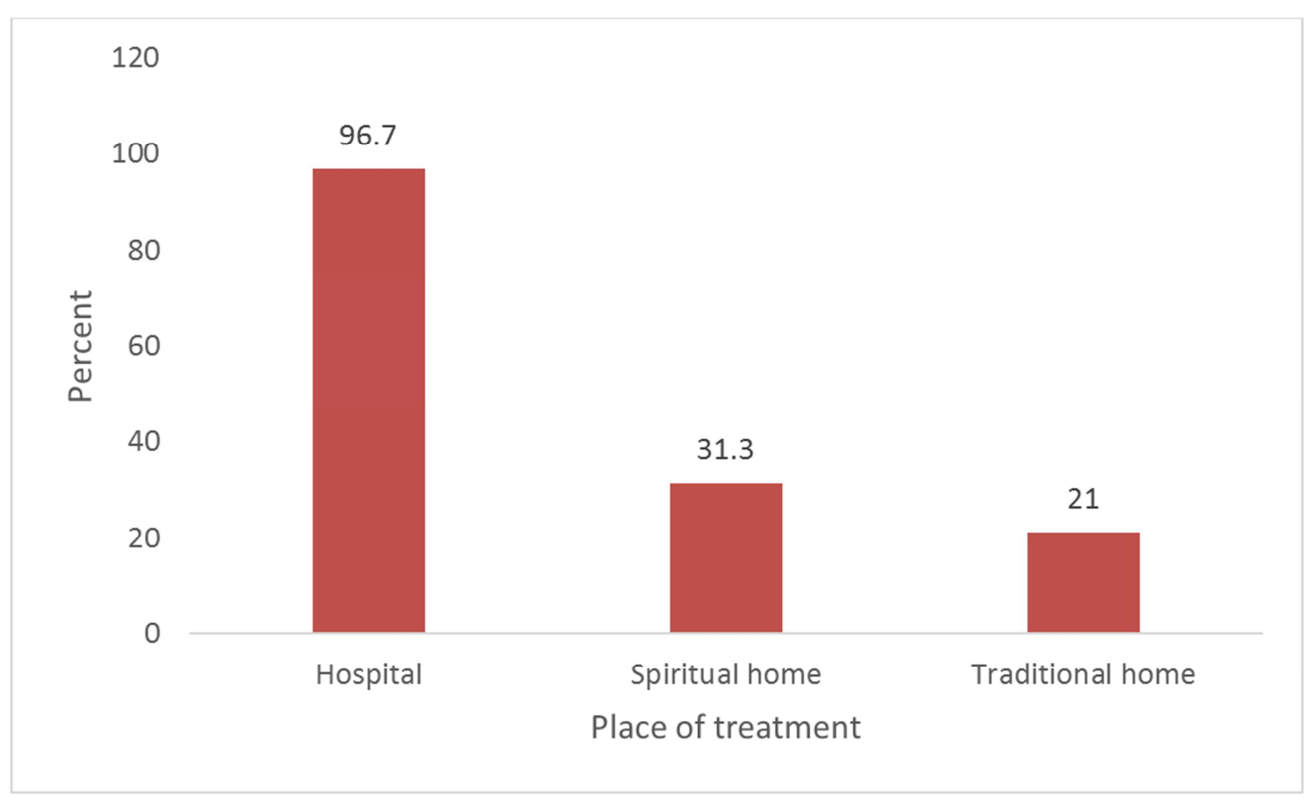

Hospital 235 (96.7\%), spiritual home 76 (31.3\%) and traditional home 51 (21.0\%)

Figure 1. Places recommended fortreatment of mental illness by respondents $(n=243)$. 


\section{Results}

Two hundred and forty three respondents participated in this study. The highest proportion of the respondents were of the age range 29-39 years (42.8\%), most respondents were female $(53.1 \%)$, majority were Muslims $(71.2 \%)$ and married $(81.1 \%)$. The highest proportion of respondents were of the Kanuri ethnic group (35\%), followed by Hausa $(21.0 \%)$ and Fulani (13.2\%). Most respondents were graduates (64.2\%), most of the respondents were nurses $(65.8 \%)$ and had worked for 8 years and more $(42.8 \%)$. (See Table 1$)$.

Table 1. Socio-demographic characteristics of respondents $(n=243)$.

\begin{tabular}{|c|c|c|c|}
\hline Characteristic & & Frequency & Percent \\
\hline \multirow{4}{*}{ Age (in years) } & $18-28$ & 34 & 14.0 \\
\hline & $29-39$ & 104 & 42.8 \\
\hline & $40-50$ & 86 & 35.4 \\
\hline & $>50$ & 19 & 7.8 \\
\hline \multirow{2}{*}{ Sex } & Male & 114 & 46.9 \\
\hline & Female & 129 & 53.1 \\
\hline \multirow{3}{*}{ Religion } & Islam & 173 & 71.2 \\
\hline & Christianity & 65 & 26.7 \\
\hline & Others & 5 & 2.1 \\
\hline \multirow{3}{*}{ Marital status } & Single & 41 & 16.9 \\
\hline & Married & 197 & 81.1 \\
\hline & Widowed & 5 & 2.1 \\
\hline \multirow{6}{*}{ Ethnic group } & Kanuri & 85 & 35.0 \\
\hline & Hausa & 51 & 21.0 \\
\hline & Fulani & 32 & 13.2 \\
\hline & Yoruba & 28 & 11.5 \\
\hline & Ibo & 13 & 5.3 \\
\hline & Others & 34 & 14.0 \\
\hline \multirow{5}{*}{$\begin{array}{l}\text { Educational } \\
\text { status }\end{array}$} & Primary & 8 & 3.3 \\
\hline & Secondary & 7 & 2.9 \\
\hline & Post-Secondary & 47 & 19.3 \\
\hline & Graduate & 156 & 64.2 \\
\hline & Postgraduate & 25 & 10.3 \\
\hline \multirow{8}{*}{ Job description } & Doctor & 41 & 16.9 \\
\hline & Nurse & 160 & 65.8 \\
\hline & Pharmacists & 2 & 0.8 \\
\hline & Lab. Scientist & 11 & 4.5 \\
\hline & Physiotherapist & 2 & 0.8 \\
\hline & Med. records officer & 4 & 1.6 \\
\hline & Admin. Staff & 10 & 4.1 \\
\hline & Ward assist./support staff & 13 & 5.3 \\
\hline \multirow{5}{*}{$\begin{array}{l}\text { Work experience } \\
\text { (in years) }\end{array}$} & $<1$ & 14 & 5.8 \\
\hline & $1-3$ & 49 & 20.2 \\
\hline & $4-6$ & 38 & 15.6 \\
\hline & $7-8$ & 38 & 15.6 \\
\hline & $>8$ & 104 & 42.8 \\
\hline \multirow{2}{*}{$\begin{array}{l}\text { Family hx of } \\
\text { mental illness }\end{array}$} & Yes & 63 & 25.9 \\
\hline & No & 180 & 74.1 \\
\hline
\end{tabular}

Most of the respondents $(56.4 \%)$ disagreed that mental illness is caused by God's punishment and majority (94.7\%) agreed orthodox treatment is preferred to other forms of treatment. (See Table2). A large proportion of the respondents $(72.1 \%)$ agreed that mentally ill patients can recover and $74.5 \%$ of them disagreed that the patients should be treated in the same hospital with other patients. (See Table 3). Majority $(82.7 \%)$ of the respondents agreed it is difficult to cope with people with mental illness in the wards, most of them $(60.9 \%)$ reported they cannot work with the mentally ill persons and $68.3 \%$ of them reported they cannot make friends with people with mental illness. (See Tables 3 and 4). A high proportion of the respondents (64.2\%) reported they were afraid of psychiatric patients admitted within the hospital while majority $(77.0 \%)$ reported they would keep a social distance because such patients are dangerous. (See Tables 4 and 5).

Table 2. Perception on the causes of mental of mental illness and treatment options by respondents.

\begin{tabular}{|c|c|c|c|c|}
\hline \multirow{2}{*}{$\begin{array}{l}\text { Perception on causes } \\
\text { of mental illness }\end{array}$} & \multicolumn{3}{|l|}{ Freq. (\%) } & \multirow{2}{*}{$\begin{array}{l}\text { Total, n } \\
(\%)\end{array}$} \\
\hline & Agree & Neutral & Disagree & \\
\hline God's punishment & $55(22.6)$ & $51(21.0)$ & $137(56.4)$ & $243(100)$ \\
\hline Witchcraft & $100(41.2)$ & $55(22.6)$ & $88(36.2)$ & $243(100)$ \\
\hline Curse & $145(59.7)$ & $30(12.3)$ & $68(28.0)$ & $243(100)$ \\
\hline Evil spirits & $164(67.5)$ & $22(09.1)$ & $57(23.4)$ & $243(100)$ \\
\hline Genetic inheritance & $215(87.7)$ & $17(07.4)$ & $11(4.9)$ & $243(100)$ \\
\hline Substance abuse & $213(87.7)$ & $18(07.4)$ & $12(04.9)$ & $243(100)$ \\
\hline Spiritual treatment & $110(45.3)$ & $37(15.2)$ & $96(39.5)$ & $243(100)$ \\
\hline Traditional treatment & $76(31.3)$ & $61(24.7)$ & $106(43.6)$ & $243(100)$ \\
\hline $\begin{array}{l}\text { Medical/ orthodox } \\
\text { treatment }\end{array}$ & $230(94.7)$ & $5(2.1)$ & $8(3.2)$ & $243(100)$ \\
\hline
\end{tabular}

Table 3. Miscellaneous beliefs and perceptions $(n=243)$.

\begin{tabular}{lll}
\hline & Frequency & Percent \\
\hline People with mental illness can recover & 175 & 72.1 \\
Agree & 38 & 15.6 \\
Neutral & 30 & 12.3 \\
Disagree & & \\
Should be treated in same hospital with other patients & 25 & 10.3 \\
Agree & 37 & 15.2 \\
Neutral & 181 & 74.5 \\
Disagree & & \\
Mentally ill patients are entitled to the same attention & 165 & 68.0 \\
Agree & 32 & 13.1 \\
Neutral & 46 & 18.9 \\
Disagree & & \\
Mental illness is contracted by physical contact & 17 & 7.0 \\
Agree & 11 & 4.5 \\
Neutral & 215 & 88.5 \\
Disagree & & \\
Difficult to cope with mentally ill patients in ward & 201 & 82.7 \\
Agree & 22 & 9.1 \\
Neutral & 20 & 8.2 \\
Disagree & & \\
\hline
\end{tabular}

Table 4. Miscellaneous perceptions ( $n=243)$.

\begin{tabular}{lll}
\hline & Frequency & Percent \\
\hline $\begin{array}{l}\text { People with mental illness should blame } \\
\text { themselves }\end{array}$ & \\
Yes & 35 & 14.4 \\
No & 208 & 85.6 \\
Afraid of talking to mentally ill & 202 & 83.1 \\
Yes & 41 & 16.9 \\
No & & \\
Can work with mentally ill & 95 & 39.1 \\
Yes & 148 & 60.9 \\
No & & \\
Can make friends with mentally ill & 77 & 31.7 \\
Yes & 166 & 68.3 \\
No & & \\
Afraid of psychiatric patient admitted within the & & \\
hospital & & \\
\hline
\end{tabular}




\begin{tabular}{lll}
\hline & Frequency & Percent \\
\hline Yes & 156 & 64.2 \\
No & 87 & 35.8 \\
Would like office near psychiatric ward & & \\
Yes & 50 & 20.6 \\
No & 193 & 79.4 \\
Want psychiatric patient treated outside the & & \\
hospital & & \\
Yes & 110 & 45.3 \\
No & 133 & 54.7 \\
\hline
\end{tabular}

Table 5. Miscellaneous attitudes ( $n=243)$.

\begin{tabular}{lll}
\hline How will you relate to mentally ill patient & Frequency & Percent \\
\hline Friendly & 27 & 11.1 \\
$\begin{array}{l}\text { With caution } \\
\begin{array}{l}\text { Keep a social distance because they are } \\
\text { dangerous }\end{array}\end{array}$ & 29 & 11.9 \\
\hline
\end{tabular}

\section{Discussion}

In this study, though majority of the respondents acknowledged that mental illness can be caused bybiological factors ranging from genetic factors to substance misuse, more than two thirds also believe evil spirits could cause mental illness. This is similar to previous studies [12], [13] where spiritual views of causation have been found to be associated with mental illness. These religious beliefs make a defensive attribution of mental illness to the influence of witchcraft or evil spirits and make them seek treatment from spiritual or traditional healers [12]. The good understanding of the biological aetiology of mental illness by the respondents in this study is not surprising given the sample of health care providers recruited for this study.

Findings from this study showed that majority of the health workers reported it is difficult to cope with persons with mental illness on the ward. This is similar to the findings of Crisp et al [14] where they expressed the same negative opinion towards the mentally ill. This could be due to deep rooted fears in the society about the dangerousness and unpredictability of people with mental illness [15]. This study also found negative attitudes of the non mental health workers towards persons with mental illness as majority of the respondents reported they cannot make friend, work or talk with mentally ill persons. This belief is due to societal attribution of violent tendencies by people with mental illness [16]. This stigmatizing attitude expressed by health workers towards people with mental illness may lead to internalized self dislike and behaviours that exacerbates the burden of the illness [17] [20]. Despite the good understanding of the biopsychosocial cause of mental illness as reported by the respondents, there was prominent negative attitudes observed in this study, this is contrary to the finding of Madianos et al [18] where they reported good knowledge positively influences attitudes towards mental illness.

With regards to social distance and mental illness, majority of the participants reported they will keep a social distance because they are dangerous. This negative attribution is likely due to possible aggressive tendencies from patients towards their caregivers and this belief is likely to promote discriminatory behaviour and stigma $[19,21]$.

\section{Conclusion}

There is need for more enlightenment, advocacy and training of health workers in mental health. This will help create a mental health friendly environment that will foster delivery of psychiatric services in a multi specialist or general hospital setting.

\section{Strength and Limitation}

The strength of this study is a hundred percent response rate among the respondents. However, important limitation is that the information was obtained through a self report interview and this might have been influenced by a need to conform to perceived cultural norms.

\section{Acknowledgements}

We are highly indebted to Dr Babagana Machina Kundi, Medical Director of Yobe State Specialist Hospital, Damaturu, Dr Zakariya Abdurrahman Ibrahim of Internal Medicine Department, Dr Hussaini Abba Disa of Dental Department of Yobe State Specialist Hospital, Damaturu, Nigeria and Psychiatric Nurse Abdullahi Mai Muhammad Nur for their collaboration, technical support, constructive feedback and facilitating data collection.

\section{References}

[1] Schulze B. Stigma and mental health professionals; a review of the evidence on an intricate relationship. IntRev Psychiatry 2007; 19; 137-155.

[2] Segal D. L, Coolidge F. L, Mincic M. S, O'Riley A. Beliefs about mental illness and willingness to seek help. A cross sectional study; Aging Mental Health 2005; 9; 363-367.

[3] Minas H, Diatri H, Pasung. Physical restraint and confinement of the mentally ill in the community. Int J. Mental Health System, 2008; 2; 8-10.

[4] Wolff G, Pathare S, Craig T, Leff J. Community knowledge of mental illness and reaction to mentally ill people. British J. Psychiatry, 1996; 168; 191-198.

[5] Corrigan P. W, Watson A. C. Understanding the impact of stigma in people with mental illness. World Psychiatric 2002; 1; 16-20

[6] Klin A, Lemish D. Mental disorders stigma in the media; review of studies on production, content and influences. J. Health Commun, 2008; 13 (5); 434-449.

[7] Hansoon L, Jorrnfeldt H, Svedberg P, Svensson B. Mental health professionals' attitudes towards people with mental illness. Do they differ from attitudes held by people with mental illness? Int J. SocPsychiatry, 2013; 59; 48-54.

[8] Brener L, Rose G, Von Hippel C, Wilson H. Implicit attitudes, emotions and helping intentions of mental health workers towards their clients. J. NervMenta Discord, 2013; 201; 6; 460-463. 
[9] Corigan P. How stigma interferes with mental health care. Am Psychol, 2004; 59(7); 614-625.

[10] Vogel D. L, Wade N. G, Haake S. Measuring the self stigma associated with seeking psychological help. J. Couns. Psychol, 2006; 53(3); 325-330.

[11] Bhugra D. Attitudes towards mental illness; a review of the literature. ActaPsychiatricaScandina, 1989; 80; 1-2.

[12] Gureje O, Olley B, Olusola E, Kola L; Do beliefs about causation influences attitudes to mental illness? World Psychiatric, 2006, 5(2); 104-1067.

[13] Ola B. A, Crabb J, Krishnadas R, Erinfolami A. R; Incidence and correlates of delirium in a West African mental health clinic. Gen Hosp Psychiatry, 2010; 32; 176-181.

[14] Crisp A. H, Gelder M. G, Rix S, Meltzer H. I. Stigmatization of people with mental illness. British J. Psychiatry, 2000; 4-7.

[15] Sherman P. Stigma, mental illness and culture.

[16] Hansson L, Jormfeldt H, Svedberg P, Svensson B. Mental health professionals attitudes towards people with mental illness. Do they differ from attitudes held by people with mental illness? Int J. Soc Psychiatry, 2013; 59; 48-54.

[17] Agbukwa N. C. Secondary school teachersattitudes'towards mental illness in Ogun State. African J. Psych 2009; 12; 5963.

[18] Madianos MG, Priami M, Alevisopoulous G, Koukia E. Nursing students attitude change towards mental illness and psychiatric case recognition after a clerkship in Psychiatry. IssMent Health Nursing, 2005; 26 (2); 169-183.

[19] Larson J. E, Corrigan; The stigma of families with mental illness. Acad Psychiatry; 2008; 32; 87-91.

[20] Ikwuka U, Ken Manktelow N, Josephine-Chen W, Oyebode F. Attitudes towards mental illness in Southeastern Nigeria: The contradictions of a communitarian culture; Journal of Community Psychology, 2016; 15(2); 10-17.

[21] Iheanacho T, Chinenye O, Osuji E, Ogidi G. Attitudes and beliefs about mental illness among church based lay health workers: experience from a prevention of mother to child HIV transmission trial in Nigeria. International Journal of Culture and Mental Health, 2016; 2; 9 (1); 1-13. 